Pak. j. sci. ind. res. Ser. A: phys. sci. 201659 (1) 11-22

\title{
Kinetics of Adsorptive Removal of Drimarene Brilliant Red from Aqueous Solution Using Untreated Agricultural Residues
}

\author{
Ch. Tahir Mehmood ${ }^{\mathrm{a}}$, Muhammad Arshad ${ }^{\mathrm{a} *}$, Tayyab Ashfaq ${ }^{\mathrm{b}}$, Muhammad Bilal ${ }^{\mathrm{c}}$, \\ Muhammad Shafiq ${ }^{c}$ and Kiran Hina ${ }^{d}$ \\ ${ }^{a}$ Institute of Environmental Sciences and Engineering (IESE), School of Civil and \\ Environmental Engineering (SCEE), National University of Sciences and Technology (NUST), \\ Sector H-12, Islamabad, 44000, Pakistan \\ ${ }^{b}$ Department of Civil Engineering, COMSATS Institute of Information Technology, University Road, \\ Abbottabad-22060, Pakistan \\ ${ }^{\mathrm{c}}$ Department of Environmental Sciences, COMSATS Institute of Information Technology, \\ University Road, Abbottabad-22060, Pakistan \\ ${ }^{\mathrm{d}}$ Department of Environmental Sciences, Hafiz Hayat Campus, University of Gujrat, \\ Gujrat, 54000, Pakistan
}

(received January 6, 2015; revised March 26, 2015; accepted April 2, 2015)

\begin{abstract}
The potential of untreated banana and orange peels, and rice husk was tested for drimarene brilliant red (DBR) dye removal from aqueous solution. Kinetics was also studied in a batch experiment. Dose of adsorbents varied from 6 to $12 \mathrm{~g} / \mathrm{L}$, particle sizes 0.2 and $0.8 \mathrm{~mm}$ and contact time 2-32 h. High dose and small particle size favoured DBR removal efficiency significantly. The highest adsorption capacity was shown by rice husk $(10 \mathrm{mg} / \mathrm{g})$, then orange peels $(9 \mathrm{mg} / \mathrm{g})$ and the lowest by banana peels $(4 \mathrm{mg} / \mathrm{g})$. Langmuir isotherm $\left(\mathrm{R}^{2}=0.99\right)$ and pseudo-second order model $\left(\mathrm{R}^{2}=0.99\right)$ depicted well the equilibrium and best explained the kinetics for rice husk, respectively. Initial adsorption appeared as pore diffusion in all the cases and film diffusion was controlling the rate, later on. Based upon the analytical data, a simple model has been presented that fitted best to describe rice husk adsorption kinetics.
\end{abstract}

Keywords: adsorption, drimarene brilliant red, banana peels, orange peels, rice husk

\section{Introduction}

Textile sector produces large quantities of wastewater that result in the release of toxic dyes into freshwater bodies. According to estimates, 12-20 tonnes/day production of finished fabric results into generation of $1,000-3,000 \mathrm{~m}^{3}$. Globally more than $1 \times 10^{7} \mathrm{~kg} /$ year of dyes stuff is produced and contributes about $1-2 \times 10^{6} \mathrm{~kg}$ of active dye into freshwater bodies annually (Prigione et al., 2012; Allen et al., 2003). These dyes are considered responsible for dermatitis, allergies, skin irritation, cell mutation and cancer. The dyes also pose serious hazards to aquatic organisms as well as affect photosynthetic activity in aquatic ecosystems. Presence of dyes in water badly affects light penetration, creating problems for photosynthetic activities in aqueous flora (Royer et al., 2009). Degradation of some dyes generates byproducts, as metabolites which are more genotoxic or carcinogenic (Zhang et al., 2011).

*Author for correspondence; E-mail: marshad@iese.nust.edu.pk
Complex molecular structure and synthetic origin of textile dyes make them stable to light, heat, oxidizing agents and microbial degradation (Sun and Yang, 2003). Conventional methods for dye removal include reverse osmosis, coagulation/flocculation, advanced oxidation, micro, ultra, and nano-filtration, and electrochemical as a tertiary treatments, as well as aerobic and anaerobic processes. Many of the aforementioned methods either have the disadvantage of producing toxic sludge, which create disposal issues, or have higher treatment costs. So there is a need for more sustainable option.

Many studies have reported the use of different adsorbents like activated carbon, peat, coir pith, chitin, silica and fly ash to remove contaminants (Royer et al., 2009; Ponnusami et al., 2007; Sun and Yang, 2003). A comprehensive list of adsorbents and target dyes is provided in a recent review (Noroozi and Sorial, 2013). Chitosan was reported as an efficient adsorbent for $90 \%$ removal of Food Yellow 3 and Acid Blue 9 (Goncalves et al., 2013). Zhang et al. (2014) have reported adsorption capacities up to 84.2, 79.6 and 
99.9\% for methyl orange, disperse blue and malachite green chloride, respectively, with a synthetic carboxymethyl cellulose-acrylic acid adsorbent. Base treated Shorea dasyphylla sawdust has been reported for the removal of acid blue 25 (Hanafiah et al., 2012).

High cost of some adsorbents, like activated carbon, is a major impediment to its application in developing countries like Pakistan. For low cost sustainable solutions, agricultural/plant residues have the potential to offer a replacement to existing costly adsorbents. Considerable efforts have been made to explore the effectiveness of plants and plant materials for textile wastewater treatment (Verma et al., 2012). However, these efforts are fragmented and more research is required using indigenous bio resources. In agricultural countries, like Pakistan, rice husk could prove a good option for sorption processes, since it is available either free of cost or at very low price. Average annual productions of rice, orange and banana during 20092013 were 6072, 2149 and 124 thousand tonnes, respectively. These led to estimated waste production of 1214, 516 and 41 thousand tonnes in the form of rice husk, orange and banana peels, respectively. The present study was conducted to compare various low cost adsorbents; banana and orange peels, and rice husk for their efficiency for drimarene brilliant red (DBR) dye removal without prior treatment. Experimental conditions such as particle size, dose and time required for maximum removal of dye were optimized. Furthermore, the mechanism of dye adsorption on various biomass materials was investigated using various isotherms and kinetic models. Finally, a very simple model is proposed which describes the adsorption by rice husk.

\section{Materials and Methods}

The adsorption potential of banana and orange peels, and rice husk was investigated for the reactive dye drimarene brilliant red (K-4BL-CDG) (Fig. 1) from aqueous dye solution.

Bio-adsorbent preparation. The banana and orange peels were obtained from a local market of Islamabad, Pakistan. Initially, the peels were washed to remove any adhering dirt and then subjected to drying, crushing and sieving to get different particle sizes ( 0.2 and 0.8 $\mathrm{mm}$ ). Rice husk was obtained from Kisan Rice Pvt. Ltd. Gujranwala, Pakistan, then air dried and sieved before use.

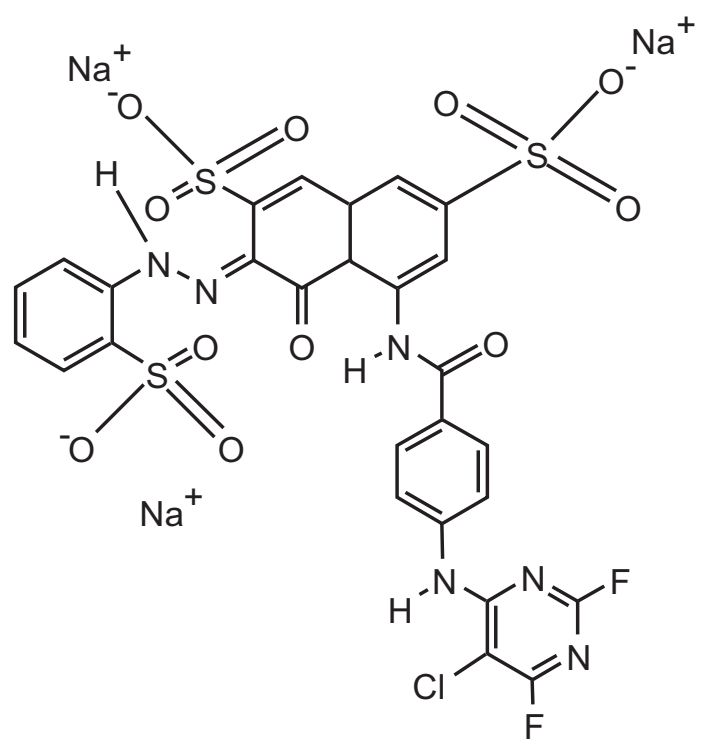

Fig. 1. Structural formula of reactive dye drimarene brilliant red (DBR).

Reagents and solutions. Drimarene brilliant red (DBR) ( $99 \%$ purity), a reactive textile dye widely used in textile industry, was purchased from Hangzhou Weiyi Chemical Co., Ltd. China, through local supplier. The stock solution $(500 \mathrm{mg} / \mathrm{L})$ of DBR was prepared by addition of $0.5 \mathrm{~g}$ of DBR in $1 \mathrm{~L}$ distilled water. The solutions of required concentrations were further prepared through dilution of the stock solution. All the tests were performed at an original solution with $\mathrm{pH}$ of 5.3. The chemical oxygen demand (COD) of the resulting dye solution was $580 \mathrm{mg} / \mathrm{L}$.

Adsorption studies. All the adsorption experiments were conducted in $250 \mathrm{~mL}$ flasks using $100 \mathrm{~mL}$ of dye solution at the original $\mathrm{pH}$. Factorial experimental design was used to perform the experiments and the factors like adsorbent dose $(\mathrm{g} / \mathrm{L})$, particle size $(\mathrm{mm})$ and contact time (h) were varied. Calculated quantities of bioadsorbents were mixed with dye solution, followed by agitation at a rate of $200 \mathrm{rpm}$ in an orbital shaker (Stauart, SSL2, UK). For adsorption kinetics experiments, constant temperature of $25^{\circ} \mathrm{C}$ was maintained. Initial adsorbent dose was varied from 6 to $12 \mathrm{~g} / \mathrm{L}$ for a total contact time from 2 to $32 \mathrm{~h}$. A sample $(3 \mathrm{~mL})$ was carefully withdrawn at desired time intervals. Each sample was analyzed after centrifugation at $4000 \mathrm{rpm}$ for $30 \mathrm{~min}$ to separate the adsorbent from dye solution. The adsorption capacity $\left(\mathrm{q}_{\mathrm{e}}\right)$ and colour removal efficiency $(R)$ were calculated using the following equations, respectively: 


$$
\begin{aligned}
& \mathrm{q}_{\mathrm{e}}(\mathrm{mg} / \mathrm{g})=\frac{\mathrm{C}_{\mathrm{t}}-\mathrm{C}_{\mathrm{o}}}{\mathrm{m}} \\
& \mathrm{R}(\%)=\frac{\mathrm{C}_{\mathrm{t}}-\mathrm{C}_{\mathrm{o}} \times 100}{\mathrm{C}_{\mathrm{o}}}
\end{aligned}
$$

where:

$\mathrm{C}_{\mathrm{o}}$ is the initial dye concentration $(\mathrm{mg} / \mathrm{L}), \mathrm{C}_{\mathrm{t}}$ is the residual dye concentration $(\mathrm{mg} / \mathrm{L})$ at time $\mathrm{t}(\mathrm{h})$ and $\mathrm{m}$ is the mass of an adsorbent $(\mathrm{g} / \mathrm{L})$.

Rate constants of decoloration were determined using exponential relation below:

$$
\operatorname{In}\left(\frac{\mathrm{C}}{\mathrm{C}_{\mathrm{o}}}\right)=-\mathrm{kt}
$$

where:

$\mathrm{C}$ was concentration of dye, time $\mathrm{t}$ and $\mathrm{C}_{\mathrm{o}}$ was initial dye concentration. A plot of $\operatorname{lnC} / C_{0}$ versus $t$ without intercept yields slope equals to $\mathrm{k}$.

Analytical procedure. The dye removal was determined at maximum absorption wavelength (530 nm) using visible spectrophotometer (HACH DR2400). The COD was determined through wet digestion by taking $2 \mathrm{~mL}$ of dye solution, $1.5 \mathrm{~mL}$ of COD reagent and $3.5 \mathrm{~mL}$ of $\mathrm{H}_{2} \mathrm{SO}_{4}$ (Boyd et al., 1947) using closed reflux colorimetric method. The COD reagent was prepared using $500 \mathrm{~mL}$ distilled water, $10.22 \mathrm{~g} \mathrm{~K}_{2} \mathrm{Cr}_{2} \mathrm{O}_{7}, 167$ $\mathrm{mL} \mathrm{H}_{2} \mathrm{SO}_{4}$ and $33.3 \mathrm{~g} \mathrm{HgSO}_{4}$ and then diluted to 1000 $\mathrm{mL}$. Afterwards, the solution was digested at $150{ }^{\circ} \mathrm{C}$ for $2 \mathrm{~h}$ using block digester (Lovibond, model ET 108, Germany), and finally titrated with ferrous ammonium sulphate (FAS) solution. Solution $\mathrm{pH}$ was recorded with digital pH meter (BMS, model pH-200L) after three stage calibration with buffers of $\mathrm{pH} 4,7$ and 10 .
Experimental design and statistical analysis. Main factors; adsorbent dose (A), particle size (B) and, contact time (C) were investigated. An analysis of variance (ANOVA) was performed to analyze the data using SPSS 17 software for the experimental design and statistical significance at 95\% confidence interval. Means were also compared using least significant difference (LSD). Multiple regression analysis was performed according to the equation given below:

$$
y=\beta_{\mathrm{o}}+\sum \beta_{\mathrm{i}} \chi_{\mathrm{i}}+\varepsilon
$$

where:

$\mathrm{y}$ is the response vector for $\mathrm{q}_{\mathrm{e}}$ (adsorption capacity) and $\mathrm{R}$ (colour removal \%). The $\beta_{\mathrm{o}}$ and $\beta_{\mathrm{i}}$ are regression coefficients for the intercept, whereas $\mathrm{x}_{\mathrm{i}}$ is the independent factor in coded units, and $\varepsilon$ is the error term (Chang et al. 2011). Coefficients of determination $\left(\mathrm{R}^{2}\right)$ were calculated to evaluate the fitness of regression model.

\section{Results and Discussion}

Screening factors for dye removal. Experimental design matrix at $32 \mathrm{~h}$ contact time is given in Table 1 , which shows adsorption capacity $\left(\mathrm{q}_{\mathrm{e}}\right)$ and colour removal (\%) of banana and orange peels, and rice husk. Adsorption capacity of the rice husk was maximum ranging from 6.0 to $10.0 \mathrm{mg} / \mathrm{g}$ followed by orange peels i.e. 5.1 to $8.7 \mathrm{mg} / \mathrm{g}$. The lowest $\mathrm{q}_{\mathrm{e}}$ was observed in case of banana peels with a maximum value of $3.7 \mathrm{mg} / \mathrm{g}$. Colour removal was also highest with the rice husk showing $84.8 \%$ removal.

Effect of adsorbent dose. Dye removal increased with increasing adsorbent doses (Table 1). Statistical significance was determined using analysis of variance

\begin{tabular}{|c|c|c|c|c|c|c|c|c|c|}
\hline \multicolumn{2}{|c|}{$\begin{array}{l}\text { Coded } \\
\text { factors }\end{array}$} & \multicolumn{2}{|c|}{ Actual factorial level } & \multicolumn{3}{|c|}{$\begin{array}{l}\text { Adsorption capacity } \\
\mathrm{q}_{\mathrm{e}}(\mathrm{mg} / \mathrm{g})\end{array}$} & \multicolumn{3}{|c|}{$\begin{array}{l}\text { Colour removal } \\
\mathrm{R}(\%)\end{array}$} \\
\hline $\bar{A}$ & $\mathrm{~B}$ & $\begin{array}{l}\text { Adsorbent } \\
\text { dose }(g / L)\end{array}$ & $\begin{array}{l}\text { Particle } \\
\text { size }(\mathrm{mm})\end{array}$ & $\begin{array}{l}\text { Banana } \\
\text { peels }\end{array}$ & $\begin{array}{l}\text { Orange } \\
\text { peels }\end{array}$ & $\begin{array}{l}\text { Rise } \\
\text { husk }\end{array}$ & $\begin{array}{l}\text { Banana } \\
\text { peels }\end{array}$ & $\begin{array}{l}\text { Orange } \\
\text { peels }\end{array}$ & $\begin{array}{l}\text { Rise } \\
\text { husk }\end{array}$ \\
\hline 1 & 1 & 6 & 0.2 & 3.7 & 8.7 & 10.0 & 22.2 & 52.3 & 59.8 \\
\hline 1 & 2 & 6 & 0.8 & 3.1 & 7.0 & 6.6 & 18.6 & 42.1 & 39.9 \\
\hline 2 & 1 & 8 & 0.2 & 3.2 & 6.8 & 9.5 & 25.9 & 54.6 & 76.1 \\
\hline 2 & 2 & 8 & 0.8 & 2.6 & 5.6 & 6.2 & 21.0 & 44.4 & 49.9 \\
\hline 3 & 1 & 10 & 0.2 & 3.1 & 5.6 & 8.1 & 30.8 & 55.6 & 80.8 \\
\hline 3 & 2 & 10 & 0.8 & 2.8 & 5.9 & 6.2 & 28.4 & 59.3 & 62.5 \\
\hline 4 & 1 & 12 & 0.2 & 2.8 & 5.3 & 7.1 & 33.7 & 63.4 & 84.8 \\
\hline 4 & 2 & 12 & 0.8 & 2.6 & 5.1 & 6.0 & 31.5 & 61.1 & 72.2 \\
\hline
\end{tabular}
(ANOVA) by general linear method of SPSS. The

Table 1. Factorial design matrix for investigated factors for adsorption capacity and colour removal after $32 \mathrm{~h}$ contact time at $25^{\circ} \mathrm{C}$ 
adsorption capacity of banana peels ranged $2.6-3.1 \mathrm{mg} / \mathrm{g}$ with the maximum colour removal of $33.7 \%$ at the highest adsorbent dose i.e. $12 \mathrm{~g} / \mathrm{L}$ (Table 1). Higher decolourisation was achieved at higher adsorbent dose i.e. $12 \mathrm{~g} / \mathrm{L}$, which was probably due to the presence of unoccupied binding sites for the attachment of dye molecules.

Effect of contact time. Statistically significant colour removal was observed with increasing contact time. Orange peels showed better adsorption capacity and colour removal efficiency (63.4\%) as compared to the banana peels with increasing contact time (Fig. 2). Rice husk was the most efficient among the tested adsorbents, achieving colour removal of $84.8 \%$ from aqueous dye solution with $12 \mathrm{~g} / \mathrm{L}$ of an adsorbent dose. Average removal efficiency at $32 \mathrm{~h}$ was slightly higher as compared to $16 \mathrm{~h}$ contact time, but there was no statistically significant difference. Colour removal was faster initially and decreased with time. In case of banana peel, most decolourisation occurred within $16 \mathrm{~h}$ of contact time. In the case of orange peel and rice husk, most decolourisation occurred within $8 \mathrm{~h}$ of contact time (Fig. 2). Colour removal rates decreased gradually which could be due to active binding site saturation and probably more time was required to bind further dye molecules with inactive or less active binding sites. Similar trends have been observed by Han et al. (2008).

Effect of particle size. Particle size significantly affected the colour removal efficiency of all the bio adsorbents under consideration (Table 1 and Fig. 2). Smaller particle size $(0.2 \mathrm{~mm})$ was strongly correlated with colour removal $\left(\mathrm{R}^{2}=0.99\right)$ as compared to the larger particle size $(0.8 \mathrm{~mm})$ with $R^{2}$ value of 0.88 . Smaller particle size $(0.2 \mathrm{~mm})$ was highly correlated $\left(\mathrm{R}^{2}=0.99\right)$ with dye removal as compared to larger particle size $(0.8 \mathrm{~mm})$. Similar results have been reported in a study (Punjongharn et al., 2008), where increase in adsorption with decrease in particle size was observed.

Regression analysis. Regression analyses displayed the leading effects of an adsorbent dose, contact time (positive) and, particle size (negative), on colour removal as compared to contact time. Following are the codified polynomial regression models for banana peels which correlate to $\mathrm{q}_{\mathrm{e}}$ and $\mathrm{R}(\%)$ :

$$
\begin{aligned}
& \mathrm{q}_{\mathrm{e}}(\mathrm{mg} / \mathrm{g})=+0.476+0.158 \mathrm{~A}-0.423 \mathrm{~B}+0.071 \mathrm{C} \\
& \mathrm{R}(\%)=+6.765+1.848 \mathrm{~A}-3.540 \mathrm{~B}+0.601 \mathrm{C}
\end{aligned}
$$

where:

A, B, C correspond to adsorbent dose, adsorbent particle size and contact time, respectively. The $\mathrm{q}_{\mathrm{e}}$ indicates adsorption capacity and $\mathrm{R}$ stands for colour removal. Factors exhibiting the positive values for their coefficients could improve the respective response vector while negative value of the coefficients suggested their inverse relationship with the response vectors. Regression analysis for orange peels revealed that dye removal was strongly affected by the particle size and adsorbent dose. The regression equations for orange peels are given as follows:

$$
\begin{aligned}
& \mathrm{q}_{\mathrm{e}}(\mathrm{mg} / \mathrm{g})=+0.045+0.296 \mathrm{~A}-1.010 \mathrm{~B}+0.126 \mathrm{C} \\
& \mathrm{R}(\%)=+5.874+3.527 \mathrm{~A}-8.590 \mathrm{~B}+1.049 \mathrm{C}
\end{aligned}
$$

Regression analysis for rice husk shows that coded factor B (particle size) displayed the greatest effect both on colour removal and adsorption capacity followed by the adsorbent dose and least effect of contact time was observed. The regression equations are as follows;

$$
\begin{aligned}
& \mathrm{q}_{\mathrm{e}}(\mathrm{mg} / \mathrm{g})=+2.024+0.512 \mathrm{~A}-2.823 \mathrm{~B}+0.064 \mathrm{C} \\
& \mathrm{R}(\%)=+7.366+6.025 \mathrm{~A}-23.91 \mathrm{~B}+0.532 \mathrm{C}
\end{aligned}
$$

Regression analysis for rice husk showed that coefficient of determination $\left(\mathrm{R}^{2}\right)$ and adjusted $\mathrm{R}^{2}$ for the model was correlated well $(0.99,0.98)$.

These findings are in accordance with the theory that larger particles have less surface area compared to the smaller particles having more surface area, for a given volume of particles. The facts are also supported by the correlation values $\left(R^{2}=0.99\right)$ for smaller particle size $(0.2 \mathrm{~mm})$. Similar trends have already been reported by Han et al. (2008) and Punjongharn et al. (2008).

According to chemical composition of banana peels, it contains about $41 \%$ carbon by weight, which is an advantage with adsorption processes. This high amount of carbon could be helpful for treating wastewater containing hazardous compounds like dyes (Palma et al., 2011). But in the same research, it has been reported that banana peel was effective only on certain dyes and it had its limitations to remove colour of textile wastewater. Since it was only able to remove $33.7 \%$ colour (Table 1 ) of DBR dye, it was inferred that banana peels cannot be used widely. However, there may be some potential if it is used after pre-treatment with an acid (Xi and Chen, 2014) or alkali and temperature variations (Crini, 2006) that will increase the treatment cost.

Regression analysis for orange peels also revealed that colour removal is strongly influenced by the particle size and adsorbent dose. Similar trends were observed for the adsorption capacity. Fair colour removal efficiency (63.4\%) with orange peels is probably due to their citrus content, 
Drimarene Brilliant Red Removal

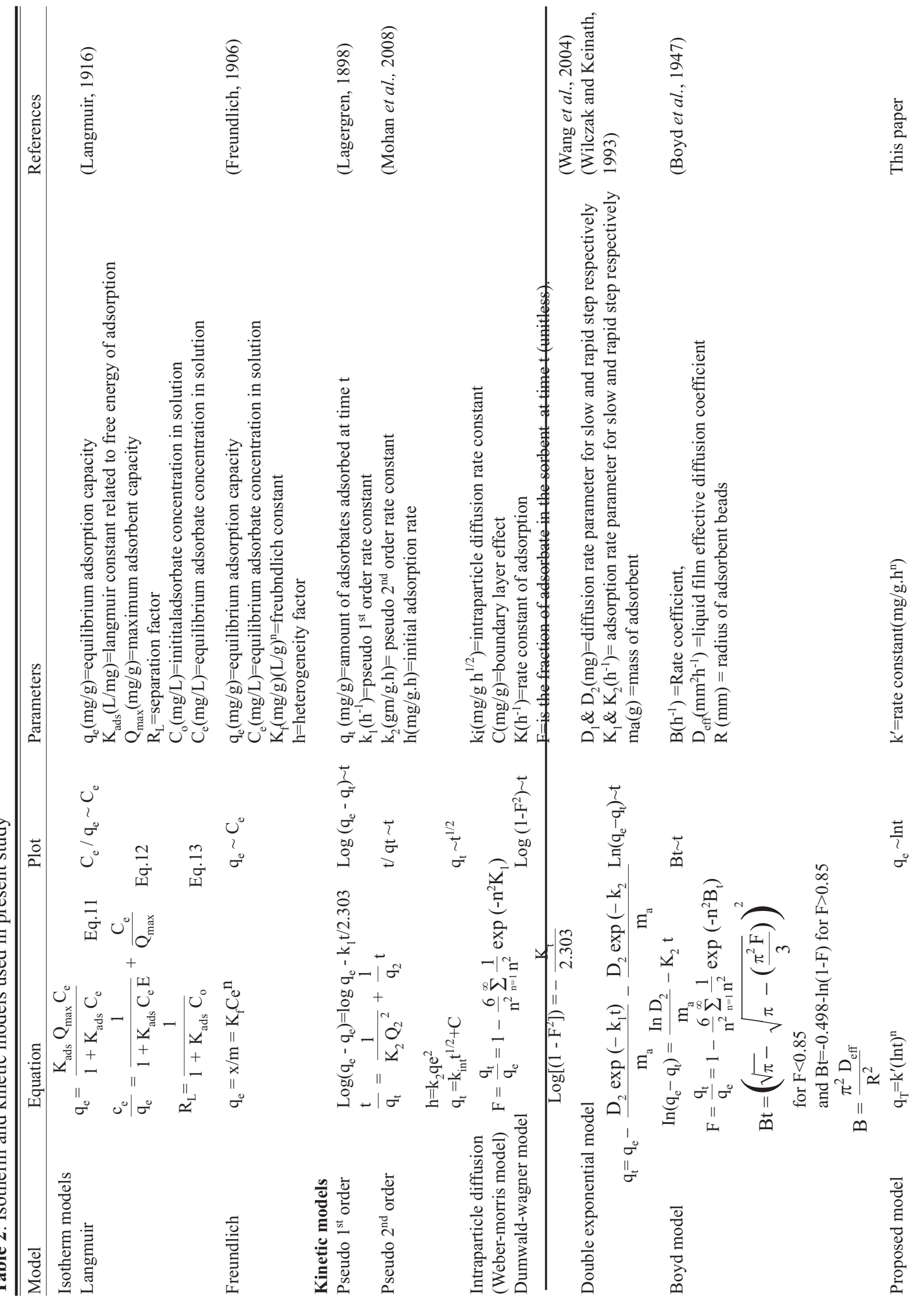


Table 3. First and second order kinetic parameters for adsorption of dye on untreated biomass

\begin{tabular}{|c|c|c|c|c|c|c|c|c|c|c|}
\hline \multirow[t]{2}{*}{ Adsorbent } & \multirow{2}{*}{$\begin{array}{l}\text { Size } \\
(\mathrm{mm})\end{array}$} & \multirow{2}{*}{$\begin{array}{l}\text { Dose } \\
\mathrm{mg} / \mathrm{L}\end{array}$} & \multirow{2}{*}{$\begin{array}{l}\mathrm{Q}_{\exp } \\
(\mathrm{mg} / \mathrm{g})\end{array}$} & \multicolumn{3}{|c|}{ First order kinetic model } & \multicolumn{3}{|c|}{ Second order kinetic model } & \multirow[t]{2}{*}{$\mathrm{R}^{2}$} \\
\hline & & & & $\begin{array}{l}\mathrm{Q}_{\text {calc }} \\
(\mathrm{mg} / \mathrm{g})\end{array}$ & $\begin{array}{l}\mathrm{K}_{1} \\
\left(\mathrm{~h}^{-1}\right)\end{array}$ & $\mathrm{R}^{2}$ & $\begin{array}{l}\mathrm{Q}_{\text {calc }} \\
(\mathrm{mg} / \mathrm{g})\end{array}$ & $\begin{array}{l}\mathrm{K}^{2} \\
\text { (mg/g.h) }\end{array}$ & $\begin{array}{l}\text { Initial } \\
\text { adsorption } \\
\text { rate } \mathrm{h}=\mathrm{k}_{2} \mathrm{qe}^{2} \\
(\mathrm{mg} / \mathrm{g} \cdot \mathrm{h})\end{array}$ & \\
\hline \multirow[t]{8}{*}{ Rice husk } & \multirow[t]{4}{*}{0.8} & 6 & 10.020 & 7.394 & 0.160 & 0.988 & 11.100 & 0.030 & 3.660 & 0.999 \\
\hline & & 8 & 9.550 & 9.940 & 0.441 & 0.956 & 10.000 & 0.102 & 10.200 & 0.997 \\
\hline & & 10 & 8.110 & 3.683 & 0.266 & 0.976 & 8.403 & 0.163 & 11.490 & 0.999 \\
\hline & & 12 & 7.110 & 2.047 & 0.155 & 0.942 & 7.300 & 0.174 & 9.260 & 0.999 \\
\hline & \multirow[t]{4}{*}{0.2} & 6 & 6.690 & 3.038 & 0.139 & 0.890 & 7.040 & 0.087 & 4.310 & 0.999 \\
\hline & & 8 & 6.270 & 4.396 & 0.204 & 0.998 & 6.700 & 0.077 & 3.460 & 0.999 \\
\hline & & 10 & 6.270 & 2.053 & 0.114 & 0.770 & 6.490 & 0.125 & 5.260 & 0.999 \\
\hline & & 12 & 6.040 & 3.125 & 0.232 & 0.989 & 6.290 & 0.159 & 6.290 & 0.999 \\
\hline \multirow[t]{8}{*}{ Orange peel } & \multirow[t]{4}{*}{0.8} & 6 & 8.796 & 13.820 & 0.234 & 0.940 & 76.923 & 8.000 & 0.311 & 0.012 \\
\hline & & 8 & 6.887 & 8.521 & 0.262 & 0.893 & 9.461 & 0.011 & 0.989 & 0.895 \\
\hline & & 10 & 5.602 & 7.405 & 0.344 & 0.865 & 7.128 & 0.020 & 1.030 & 0.932 \\
\hline & & 12 & 5.324 & 26.687 & 0.698 & 0.907 & 6.780 & 0.022 & 0.995 & 0.918 \\
\hline & \multirow[t]{4}{*}{0.2} & 6 & 7.099 & 9.759 & 0.145 & 0.972 & 85.470 & 0.000 & 0.263 & 0.006 \\
\hline & & 8 & 5.613 & 8.656 & 0.306 & 0.974 & 9.074 & 0.007 & 0.595 & 0.542 \\
\hline & & 10 & 4.954 & 8.488 & 0.290 & 0.968 & 7.353 & 0.012 & 0.651 & 0.812 \\
\hline & & 12 & 4.128 & 3.499 & 0.051 & 1.000 & 5.519 & 0.020 & 0.595 & 0.848 \\
\hline \multirow[t]{8}{*}{ Banana peel } & \multirow[t]{4}{*}{0.8} & 6 & 3.749 & 10.703 & 0.281 & 0.878 & -2.771 & 0.008 & 0.062 & 0.327 \\
\hline & & 8 & 3.270 & 4.242 & 0.096 & 0.971 & 62.112 & 0.000 & 0.115 & 0.005 \\
\hline & & 10 & 3.105 & 3.929 & 0.182 & 0.964 & 5.359 & 0.010 & 0.280 & 0.599 \\
\hline & & 12 & 2.832 & 4.158 & 0.281 & 0.981 & 3.392 & 0.056 & 0.647 & 0.979 \\
\hline & \multirow[t]{4}{*}{0.2} & 6 & 3.178 & 5.390 & 0.149 & 0.878 & -2.620 & 0.008 & 0.053 & 0.433 \\
\hline & & 8 & 2.689 & 4.094 & 0.142 & 0.936 & -33.33 & 0.000 & 0.091 & 0.021 \\
\hline & & 10 & 2.861 & 3.776 & 0.176 & 0.923 & 5.528 & 0.007 & 0.222 & 0.495 \\
\hline & & 12 & 2.649 & 3.926 & 0.230 & 0.941 & 3.577 & 0.029 & 0.374 & 0.932 \\
\hline
\end{tabular}

which is capable of binding dye molecules (Sivaraj et al., 2001). Orange peel contains carboxyl and hydroxyl groups and adsorption capacity improves with increase in carboxyl and hydroxyl content. These properties make it a suitable material for adsorption of a wide range of contaminants. It is found that orange peel contains relatively high content of pectin which plays an important role in adsorption.

Regression analysis for rice husk showed that coefficient of determination $\left(\mathrm{R}^{2}\right)$ and adjusted $\mathrm{R}^{2}$ for the model was correlated well $(0.99,0.98)$. Minor difference in these values infers that there was a negligible possibility of adding any insignificant term in these regression models (Chang et al., 2011). The normal distribution of the predicted values along respective mean values confirmed the appropriateness of the regression models to explain colour removal efficiency and adsorption capacity according to eq. (9) and eq. (10).

Adsorption isotherms. Various isotherm models as well as kinetic models used in present study are shown in Table 2. Langmuir and Freundlich isotherms were selected from several isotherm equations, eq. 11, 12 and 13 already used in the literature (Langmuir, 1916; Freundlich, 1906). In the Langmuir isotherm, it is supposed that adsorption occurs at specific homogeneous sites on surface of an adsorbent and there are no significant interactions within adsorbed species. The adsorbent surface is saturated by a single layer of adsorbent molecules. The linearized Langmuir isotherm equation also known as Hanes-Woolf plot is represented by eq. 11 (Table 2). Linear relationships of rice husk for both particle sizes were found $\left(\mathrm{R}^{2}=0.99\right)$. This indicates suitability of the model to explain the adsorption process equilibrium (Wu et al., 2007) for rice husk. The closeness of calculated $\mathrm{q}_{\mathrm{m}}(7.2 \mathrm{mg} / \mathrm{g})$ and experimental adsorption capacity $(6.7 \mathrm{mg} / \mathrm{g})$ confirmed the validity of this model for the adsorbent.

Langmuir isotherm's characteristics are expressed by equilibrium parameter $R_{L}$ which is a dimension less 


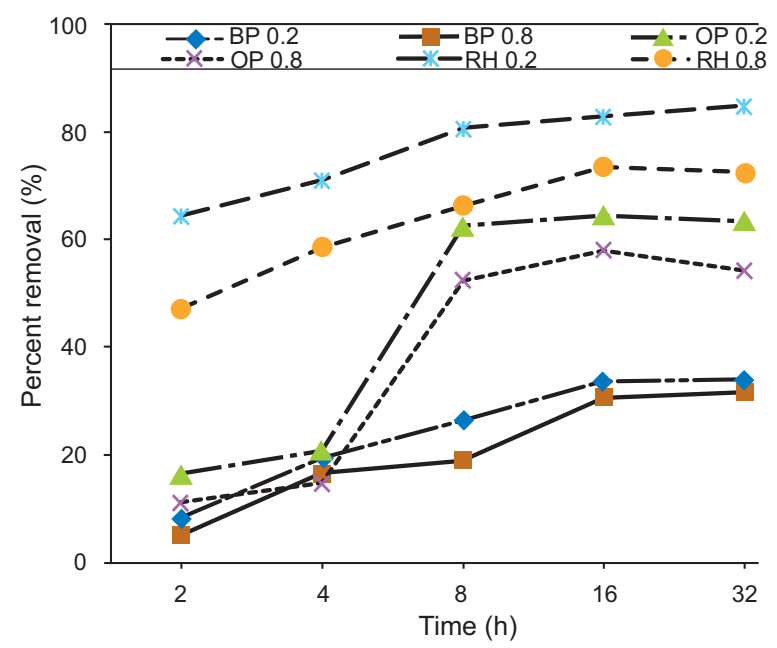

Fig. 2. Effect of contact time on adsorption capacity of different bioadsorbents. $\mathrm{BP}=$ banana peel; $\mathrm{OP}=$ orange peel; $\mathrm{RH}=$ rice husk; 0.2 and $0.8 \mathrm{~mm}$ sizes.

constant that measures the favourability and shape of the adsorption isotherm of using eq. 13 (Table 2). The $\mathrm{R}_{\mathrm{L}}$ value determines either the isotherm is linear $\left(\mathrm{R}_{\mathrm{L}}=1\right)$, favourable $\left(0<\mathrm{R}_{\mathrm{L}}<1\right)$, unfavourable $\left(\mathrm{R}_{\mathrm{L}}>1\right)$ or irreversible $\left(\mathrm{R}_{\mathrm{L}}=0\right)$. The Freundlich model can be used to explain multilayer and heterogeneous adsorption on surfaces (Freundlich, 1906). Power series regression analysis of the plot of $\mathrm{q}_{\mathrm{e}}$ against $\mathrm{C}_{\mathrm{e}}$ resulted into correlation coefficients' $\left(\mathrm{R}^{2}\right)$ value of less than 0.944 . This indicated that the Freundlich plots did not agree well with the experimental data.

For similar adsorption studies, Langmuir model has been applied and reported (Low et al., 2011). Orange and banana peel did not follow the Langmuir model (Table 2). Also, the parameters for Langmuir model came out to be negative, which does not have any physical significance. All the values of $R_{L}$ calculated from the Langmuir equation ranged between $0-1$ for rice husk highlighting the fact that adsorption process was favourable for both particle sizes. This provided the evidence that, rice husk can be used for the commercial scale treatment of dye wastewater. In all the other cases Langmuir model gave fairly low $\mathrm{R}^{2}$ value in most cases indicating that this model cannot be applied on other biomass materials.

Adsorption kinetics. Kinetics is a significant aspect in assessment of sorption potential of any substance. The kinetic constants can help to adjust residence conditions for dye adsorption. For the adsorption of

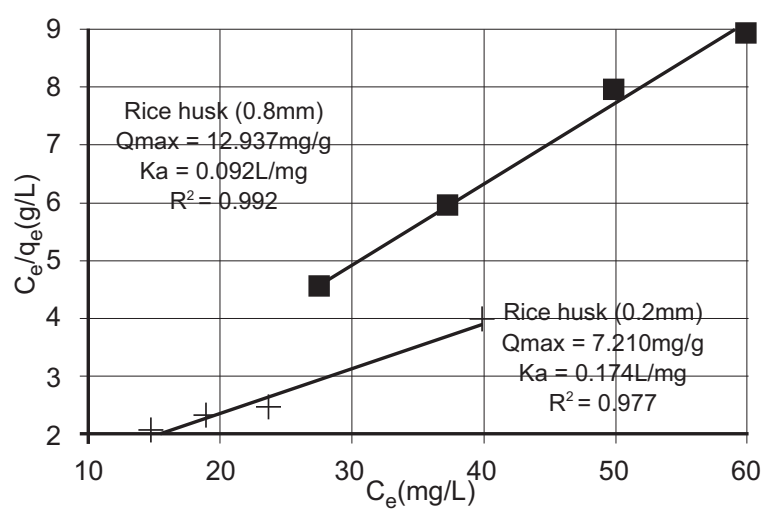

Fig. 3. Langmuir isotherm plot for the adsorption of DBR dye on rice husk (contact time $=$ $32 \mathrm{~h} ; \mathrm{pH}=5.3$; temperature $=25^{\circ} \mathrm{C}$ ).

DBR dye on rice husk after $32 \mathrm{~h}$ of contact time, Langmuir isotherm plot is presented in Fig. 3. The rate of achieving equilibrium on the large particle size of rice husk was quicker than that of smaller particle size. Kinetic models usually used in literature are divided into following two categories: (a) Adsorption reaction models (b) Adsorption diffusion models;

The adsorption capacities of larger particle size were lesser than those of small particle size. Large sized particles reached equilibrium earlier because of small surface area as compared to fine particles having large surface area. Three mass transport steps are linked in adsorption process (Wu et al., 2007). In the first step, adsorbate moves through the solution to reach external surface of adsorbent by molecular diffusion (film or external diffusion). Then solute movement takes place by pore diffusion from surface of the particle into interior site. In the final step, adsorption of adsorbate takes place on the active sites. The phenomenon requires relatively longer contact time (Crini, 2006).

Orange and banana peels seem to follow pseudo $1^{\text {st }}$ order kinetics with correlation coefficient. Rice husk did not give a strong correlation $\left(\mathrm{R}^{2}=0.77-0.99\right)$ in most cases. Pseudo-first order reaction model also indicates film diffusion as rate controlling process. Hence, in case of orange peel and banana peel film diffusion seemed to be rate controlling. The rice husk seems to follow pseudo-second order kinetics quite well. The $\mathrm{R}^{2}$ values for two particle sizes were found as 0.99 which shows that the adsorption of DBR on rice husk followed pseudo-second order kinetic model (Arami et al., 2005). The average percentage error between calculated and experimental capacity was less than $5 \%$. There seems to be strong correlation between experimental and 
calculated capacity (Table 3). Hence, this model can be used to calculate adsorption capacity of rice husk for DBR. Usually initial adsorption rate decreases with particle size except at low solids concentration $(6 \mathrm{~g} / \mathrm{L})$. The initial faster rate of dye adsorption onto rice husk could be due to the presence of higher number of unused binding sites.

Dumwald-Wagner Model, Boyd, double exponential and Weber-Morris models were used to get mechanisms of adsorption kinetics. Dumwald-Wagner model gave good correlations for most of the combinations like 0.85 to 0.96 for the banana peel. However, in no case, the plot passed through the origin, which shows that the intra-particle diffusion was not the sole process controlling adsorption.

Weber-Morris model showed that the intercept did not pass through the origin (Fig. 4), which indicated the existence of boundary layer effect to some extent, and there was difference in mass transfer rate during initial and final stages of adsorption process (Akar et al., 2008). The value of $C 1$ in case of orange and banana peel came out to be negative which does not have any physical significance and indicates that diffusion through the boundary layer was not rate limiting in initial stages of adsorption (Table 4). There seems to be two (rice husk and orange peel) or three (banana peel) different regimes involved (Fig. 4). In the first regime $(0-8 \mathrm{~h})$ boundary layer effect is small and adsorption seems to

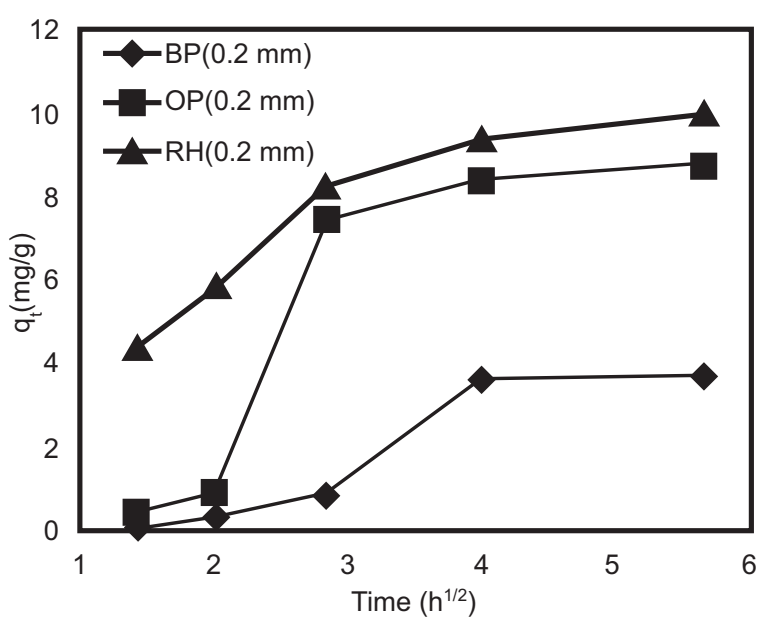

Fig. 4. Intra-particle diffusion model of DBR adsorption for biomasses at $6 \mathrm{~g} / \mathrm{L}$ dose of $0.2 \mathrm{~mm}$ particle size. $\mathrm{BP}=$ banana peel; $\mathrm{OP}=$ orange peel; rice husk $=\mathrm{RH}, 0.2$ and $0.8 \mathrm{~mm}$ sizes. be mainly controlled by pore diffusion. This represented surface adsorption and immediate use of readily available sorption sites (Chang et al., 2003). There is strong correlation (average $\mathrm{R}^{2}=0.98$ ) for first regime in case of rice husk. However, banana and orange peel did not give strong correlations (average $\mathrm{R}^{2}=0.91$ ) in most cases. In the second regime (8-32 h) there was a large boundary layer effect, which was indicated by a marked increase in y-intercept of curve for second regime. This could be due to very slow adsorbate diffusion and more time required reaching inner pores from the surface (Mohan et al., 2008). The second regime did not give strong correlation $\left(\mathrm{R}^{2}=0.70\right)$ for all biomass used. In the case of banana peel, there is an additional transition region (8-16 h) in many cases.

Adsorption reaction models. Adsorption reaction models originating from chemical reaction kinetics are dependent on the complete adsorption process without considering the actual mechanism of transport of contaminant due to diffusion. The kinetic adsorption data is treated first to find out the order of rate constant. The following reaction models were used:

Lagergren's pseudo first order reaction model. This model (Table 3 ) is the earliest known and adsorption capacity is considered to describe the adsorption rate. A pseudo first order model has been generally used for description of pollutants adsorption mainly from wastewater. For example, methylene blue adsorption using broad bean peels from aqueous solution and malachite green removal from aqueous solutions with oil palm trunk fibre (Hameed and El-Khaiary, 2008). It was first used to treat kinetic data. Values of the equilibrium adsorption capacity $\left(\mathrm{q}_{\mathrm{e}}\right)$, rate constant $\left(\mathrm{k}_{1}\right)$ and the correlation coefficients $\left(\mathrm{R}^{2}\right)$ were calculated from $\log \left(\mathrm{q}_{\mathrm{e}}-\mathrm{q}_{\mathrm{t}}\right)$ versus $\mathrm{t}$ plots as shown in Table 5 . Orange and banana peels seem to follow psuedo $1^{\text {st }}$ order kinetics $\left(\mathrm{R}^{2}=0.91-0.98\right)$.

Pseudo second order rate expressions. In next step, pseudo-second order model was tested. In this model, it is assumed that the chemisorption may be the rate-limiting step. Chemisorption involves valence forces through exchange or sharing of electrons between sorbate and sorbent. Rate constant of this model is a complex function of the initial solute concentration. The driving force, $\left(\mathrm{q}_{\mathrm{e}}-\mathrm{q}_{\mathrm{t}}\right)$, is directly proportional to the available fraction of active sites. The equation for this model has the advantages like; there is no problem in assigning the effective adsorption capacity, i.e., the rate constant of pseudo second order, the 
adsorption capacity, and the initial adsorption rate, these can be calculated from the equation, without any need to know any particular parameter beforehand. This model was applied by plotting $\mathrm{t} / \mathrm{q}_{\mathrm{t}}$ vs $\mathrm{t}$. The parameters; rate constant $\left(\mathrm{k}_{2}\right)$ and initial adsorption rate $\left(\mathrm{h}=\mathrm{k}_{2} \mathrm{q}_{\mathrm{e}}{ }^{2}\right)$, were determined from the intercept and the slope of plot.

Adsorption diffusion models. On the basis of previous studies, it can be claimed that adsorption kinetics are always controlled by intra-particle diffusion or liquid film diffusion (Meng, 2005). So adsorption diffusion models are developed to explain the film diffusion and/or the process of intra particle diffusion.

Dumwald-Wagner model. Dumwald-Wagner proposed another intra-particle diffusion model (Wang et al., 2004). This model gave fairly good correlations for most of the combinations and $\mathrm{R}^{2}$ value was above 0.90 , whereas, for banana peels it ranged from 0.85 to 0.96 (Table 5).
Boyd's model. The Boyd's model (Boyd et al., 1947) is often used to explain the adsorption kinetics mechanism. Originally proposed for intra-particle diffusion in a spherical particle, it is better known as the Boyd's film-diffusion model. It allows identification of the slowest stage between intra-particle diffusion and film-diffusion. Although the plot of $B_{t}$ versus $t$ is linear but does not pass through the origin, which indicates that the process is controlled by film diffusion. The effective diffusion coefficient, $\mathrm{D}_{\text {eff }}\left(\mathrm{mm}^{2} / \mathrm{h}\right)$ is as calculated in Table 5.

Double-exponential model (DEM). A doubleexponential function proposed was used to describe lead and copper adsorption onto activated carbon (Wilczak and Keinath, 1993). In this model, the uptake process is divided into two steps, a rapid phase for external and internal diffusions and then a slow phase involving intra-particle diffusion. It was demonstrated

Table 4. Kinetic parameters for Weber-Morris model and proposed model for adsorption of dye on untreated biomass at different dosage level

\begin{tabular}{|c|c|c|c|c|c|c|c|c|c|c|c|}
\hline \multirow[t]{2}{*}{ Adsorbent } & \multirow{2}{*}{$\begin{array}{l}\text { Size } \\
(\mathrm{mm})\end{array}$} & \multirow{2}{*}{$\begin{array}{l}\text { Dose } \\
(\mathrm{mg} / \mathrm{L})\end{array}$} & \multicolumn{6}{|c|}{ Weber - Morris model } & \multicolumn{3}{|c|}{ Proposed model } \\
\hline & & & $\begin{array}{l}\mathrm{K}_{\mathrm{id} 1} \\
\left(\mathrm{mg} / \mathrm{g} \cdot \mathrm{h}^{1 / 2}\right)\end{array}$ & $\begin{array}{l}\mathrm{C}_{1} \\
(\mathrm{mg} / \mathrm{g})\end{array}$ & $\mathrm{R}^{2}$ & $\begin{array}{l}\mathrm{K}_{\mathrm{id} 2} \\
\left(\mathrm{mg} / \mathrm{g} \cdot \mathrm{h}^{1 / 2}\right)\end{array}$ & $\begin{array}{l}\mathrm{C}_{2} \\
\left(\mathrm{mg} / \mathrm{g} \cdot \mathrm{h}^{1 / 2}\right)\end{array}$ & $\mathrm{R}^{2}$ & $\begin{array}{l}\mathrm{K}^{\prime} \\
\left(\mathrm{mg} / \mathrm{g} \cdot \mathrm{h}^{1 / 2}\right)\end{array}$ & $\mathrm{N}$ & $\mathrm{R}^{2}$ \\
\hline \multirow[t]{8}{*}{ Rice husk } & 0.8 & 6 & 2.734 & 0.493 & 0.998 & 0.602 & 6.724 & 0.929 & 5.278 & 0.539 & 0.979 \\
\hline & & 8 & 2.186 & 3.026 & 0.987 & 0.075 & 9.247 & 0.145 & 6.920 & 0.304 & 0.915 \\
\hline & & 10 & 1.100 & 0.452 & 0.989 & 0.136 & 7.433 & 0.516 & 6.510 & 0.195 & 0.937 \\
\hline & & 12 & 0.928 & 4.070 & 1.000 & 0.145 & 6.301 & 0.983 & 5.720 & 0.182 & 0.977 \\
\hline & 0.2 & 6 & 1.615 & 1.554 & 0.977 & 0.232 & 5.376 & 1.000 & 4.359 & 0.371 & 0.979 \\
\hline & & 8 & 1.308 & 1.654 & 0.996 & 0.299 & 4.672 & 0.813 & 3.970 & 0.383 & 0.967 \\
\hline & & 10 & 1.270 & 2.283 & 0.948 & 0.181 & 5.212 & 0.925 & 4.489 & 0.285 & 0.967 \\
\hline & & 12 & 1.091 & 2.528 & 0.956 & 0.162 & 5.233 & 0.495 & 4.440 & 0.281 & 0.972 \\
\hline \multirow[t]{8}{*}{ Orange peel } & 0.8 & 6 & 5.161 & -7.781 & 0.872 & 0.448 & 6.364 & 0.894 & 0.869 & 2.087 & 0.887 \\
\hline & & 8 & 3.763 & -4.492 & 0.956 & 0.160 & 6.010 & 0.943 & 1.910 & 1.089 & 0.924 \\
\hline & & 10 & 2.998 & 3.307 & 0.924 & 0.048 & 5.342 & 0.919 & 1.870 & 1.011 & 0.886 \\
\hline & & 12 & 2.825 & -3.075 & 0.893 & 0.021 & 5.250 & 0.093 & 1.830 & 0.980 & 0.850 \\
\hline & 0.2 & 6 & 2.782 & -3.885 & 0.963 & 0.952 & 2.286 & 0.556 & 0.600 & 2.111 & 0.971 \\
\hline & & 8 & 2.692 & -2.650 & 0.804 & 0.365 & 3.708 & 0.704 & 1.309 & 1.450 & 0.837 \\
\hline & & 10 & 2.455 & -2.885 & 0.983 & 0.226 & 4.027 & 0.158 & 1.256 & 1.321 & 0.943 \\
\hline & & 12 & 2.517 & -3.026 & 0.887 & 0.119 & 4.956 & 0.206 & 1.330 & 1.103 & 0.828 \\
\hline \multirow[t]{8}{*}{ Banana peel } & 0.8 & 6 & 0.408 & -0.380 & 0.949 & 0.043 & 3.471 & 1.000 & 0.178 & 2.538 & 0.969 \\
\hline & & 8 & 0.517 & -0.397 & 0.990 & 0.713 & -0.614 & 0.913 & 0.309 & 1.949 & 0.995 \\
\hline & & 10 & 0.795 & -0.334 & 0.883 & 0.411 & 0.920 & 0.793 & 0.643 & 1.447 & 0.917 \\
\hline & & 12 & 0.754 & 0.000 & 0.981 & 0.210 & 1.734 & 0.714 & 1.660 & 0.899 & 0.960 \\
\hline & 0.2 & 6 & 0.285 & -0.309 & 0.990 & 0.904 & -1.617 & 0.786 & 0.155 & 2.366 & 0.933 \\
\hline & & 8 & 0.528 & -0.641 & 0.967 & 0.610 & -0.572 & 0.827 & 0.252 & 1.904 & 0.959 \\
\hline & & 10 & 0.773 & -0.573 & 0.643 & 0.484 & 0.300 & 0.773 & 0.541 & 1.489 & 0.908 \\
\hline & & 12 & 0.770 & -0.461 & 0.808 & 0.353 & 0.799 & 0.724 & 0.761 & 1.105 & 0.951 \\
\hline
\end{tabular}


Table 5. Kinetic parameters for Dumwald-Wagner, double exponential and Boyd model for adsorption of dye on untreated biomass at different dosage level

\begin{tabular}{|c|c|c|c|c|c|c|c|c|c|}
\hline \multirow[t]{2}{*}{ Adsorbent } & \multirow{2}{*}{$\begin{array}{l}\text { Size } \\
(\mathrm{mm})\end{array}$} & \multirow{2}{*}{$\begin{array}{l}\text { Dose } \\
(\mathrm{mg} / \mathrm{L})\end{array}$} & \multicolumn{2}{|c|}{ Dumwald-wagner model } & \multicolumn{3}{|c|}{ Double exponential model } & \multicolumn{2}{|c|}{ Boyds model } \\
\hline & & & $\begin{array}{l}\mathrm{K}_{1} \\
\left(\mathrm{~h}^{-1}\right)\end{array}$ & $\mathrm{R}^{2}$ & $\begin{array}{l}\mathrm{K}_{2} \\
\left(\mathrm{~h}^{-1}\right)\end{array}$ & $\begin{array}{l}\mathrm{D}_{2} \\
(\mathrm{mg})\end{array}$ & $\mathrm{R}^{2}$ & $\begin{array}{l}\mathrm{D}_{\text {eff }} \\
\left(\mathrm{cm}^{2} / \mathrm{h}\right)\end{array}$ & $\mathrm{R}^{2}$ \\
\hline \multirow[t]{8}{*}{ Rice husk } & \multirow[t]{4}{*}{0.8} & 6 & 0.140 & 0.993 & 0.160 & 4.437 & 0.988 & $1.327 \mathrm{E}-06$ & 0.991 \\
\hline & & 8 & 0.411 & 0.950 & 0.441 & 7.953 & 0.956 & $6.678 \mathrm{E}-06$ & 0.953 \\
\hline & & 10 & 0.248 & 0.973 & 0.265 & 3.683 & 0.976 & $3.645 \mathrm{E}-06$ & 0.975 \\
\hline & & 12 & 0.148 & 0.947 & 0.155 & 2.456 & 0.942 & $3.237 \mathrm{E}-06$ & 0.943 \\
\hline & \multirow[t]{4}{*}{0.2} & 6 & 0.126 & 0.904 & 0.139 & 1.823 & 0.890 & $3.209 \mathrm{E}-05$ & 0.897 \\
\hline & & 8 & 0.188 & 0.994 & 0.204 & 3.270 & 0.998 & $6.103 \mathrm{E}-05$ & 0.996 \\
\hline & & 10 & 0.103 & 0.781 & 0.114 & 2.053 & 0.770 & 4.399E-05 & 0.775 \\
\hline & & 12 & 0.209 & 0.994 & 0.232 & 3.749 & 0.989 & $4.582 \mathrm{E}-05$ & 0.991 \\
\hline \multirow[t]{8}{*}{ Orange peel } & \multirow[t]{4}{*}{0.8} & 6 & 0.187 & 0.963 & 0.233 & 8.292 & 0.940 & $8.700 \mathrm{E}-07$ & 0.959 \\
\hline & & 8 & 0.225 & 0.908 & 0.262 & 6.817 & 0.893 & $2.911 \mathrm{E}-06$ & 0.904 \\
\hline & & 10 & 0.310 & 0.876 & 0.344 & 7.405 & 0.865 & $1.560 \mathrm{E}-06$ & 0.869 \\
\hline & & 12 & 0.620 & 0.900 & 0.698 & 32.028 & 0.907 & $1.791 \mathrm{E}-06$ & 0.9 \\
\hline & \multirow[t]{4}{*}{0.2} & 6 & 0.074 & 0.928 & 0.145 & 5.761 & 0.972 & $3.488 \mathrm{E}-06$ & 0.923 \\
\hline & & 8 & 0.272 & 0.964 & 0.306 & 6.924 & 0.974 & 7.157E-05 & 0.968 \\
\hline & & 10 & 0.211 & 0.939 & 0.290 & 8.488 & 0.968 & $1.150 \mathrm{E}-05$ & 0.936 \\
\hline & & 12 & 0.022 & 1.000 & 0.051 & 4.207 & 1.000 & $4.183 \mathrm{E}-06$ & 1.000 \\
\hline \multirow[t]{8}{*}{ Banana peel } & \multirow[t]{4}{*}{0.8} & 6 & 0.233 & 0.850 & 0.280 & 6.421 & 0.878 & $5.497 \mathrm{E}-07$ & 0.848 \\
\hline & & 8 & 0.073 & 0.919 & 0.111 & 3.394 & 0.971 & $2.267 \mathrm{E}-07$ & 0.913 \\
\hline & & 10 & 0.148 & 0.944 & 0.182 & 3.929 & 0.964 & 4.913E-07 & 0.944 \\
\hline & & 12 & 0.252 & 0.964 & 0.281 & 4.990 & 0.981 & $1.261 \mathrm{E}-06$ & 0.968 \\
\hline & \multirow[t]{4}{*}{0.2} & 6 & 0.105 & 0.888 & 0.148 & 3.234 & 0.878 & $4.137 \mathrm{E}-06$ & 0.846 \\
\hline & & 8 & 0.101 & 0.838 & 0.142 & 3.275 & 0.936 & $2.684 \mathrm{E}-06$ & 0.883 \\
\hline & & 10 & 0.142 & 0.899 & 0.176 & 3.776 & 0.923 & $6.334 \mathrm{E}-06$ & 0.897 \\
\hline & & 12 & 0.203 & 0.916 & 0.230 & 4.710 & 0.941 & $1.394 \mathrm{E}-05$ & 0.917 \\
\hline
\end{tabular}

that the two-step mechanism can be described fairly well with the double-exponential model (Table 5). If $\mathrm{K}_{1}>\mathrm{K}_{2}$, this means that the contribution of rapid process on the overall kinetics can be assumed to be negligible hence, this can be simplified as and be rearranged to a linear form.

Weber-morris model. This model $\left(\mathrm{q}_{\mathrm{t}}=\mathrm{k}_{\text {int }} \mathrm{t}^{1 / 2}+\mathrm{C}\right)$ helps us to understand intra-particle diffusion. In this model, $\mathrm{k}_{\text {int }}$ is the intra-particle diffusion rate constant $(\mu \mathrm{g} / \mathrm{g}$ $\left.\min ^{1 / 2}\right)$ and $\mathrm{C}(\mu \mathrm{g} / \mathrm{g})$ is a constant linked to thickness of the boundary layer. Its higher value means larger boundary layer effect and vice versa. The plot of $\mathrm{q}_{\mathrm{t}}$ versus $\mathrm{t}^{1 / 2}$ would result in a linearised relationship. Diffusion would be the rate limiting step if the line passes through the origin. If it is not so, the intra-particle diffusion is responsible for the sorption but it might not be the only step controlling sorption rate. Boundary layer control and some other processes occurring at the same time may also be responsible. In all the cases it is clear that adsorption is not diffusion controlled and boundary layer has significant effect on the overall adsorption rate as well as capacity.

Proposed kinetic model. It was found that in most cases the adsorption kinetic seems to follow the empirical model " $\mathrm{q}_{\mathrm{t}}=\mathrm{K}$ '(lnt) $)^{\mathrm{n}}$,

where:

" $\mathrm{q}_{\mathrm{t}}$ " is the adsorption capacity at time " $\mathrm{t}$ ". This model gave a very good correlation in most of the cases as shown in Table 4.

\section{Conclusion}

Out of the three bio adsorbents used, rice husk was the most effective for removal of DBR dye. The optimised conditions for the maximum colour removal efficiency at $25{ }^{\circ} \mathrm{C}$ using rice husk were $0.2 \mathrm{~mm}$ particle size, $12 \mathrm{~g} / \mathrm{L}$ dose of adsorbent and $16 \mathrm{~h}$ contact time. In the case of rice husk, initial adsorption seemed to be intra- 
particle pore diffusion controlled, while later on, film diffusion appeared as the rate limiting mechanism. Adsorption models and kinetic studies indicated the potential of using untreated rice husk as an effective adsorbent. These findings can help us in developing cost-effective remediation process for coloured/textile wastewater. The utilization of such biomass in fixed bed reactor designs for dyes removal from wastewaters needs to be tested.

\section{Acknowledgement}

The research was supported and funded by Science and Technology Fund, National University of Sciences and Technology (NUST), Islamabad, Pakistan. We thank Dr. M. Ali Awan for his support and guidance on technical issues during the study. Authors would also like to thank Dr. James Hanly, Institute of Agriculture and Environment, Massey University, New Zealand for critical review and corrections at first stage.

\section{References}

Akar, T., Ozcan, S.A., Tunali, S., Ozcan, A. 2008. Biosorption of a textile dye (Acid Blue 40) by cone biomass of Thuja orientalis: Estimation of equilibrium, thermodynamic and kinetic parameters. Bioresource Technology, 99: 3057-3065.

Allen, S.J., Gan, Q., Matthews, R. Johnson, P.A. 2003. Comparison of optimised isotherm models for basic dye adsoption by kudzu. Bioresource Technology, 88: $143-152$.

Arami, M., Limaee, N.Y., Mahmoodi, N.M., Tabrizi, N.S. 2005. Removal of dyes from colored textile wastewater by orange peel adsorbent: equilibrium and kinetic studies. Journal of Colloid and Interface Science, 288: 371-376.

Boyd, G.E., Adamson, A,W., Myers Jr., L.S. 1947. The exchange adsorption of ions from aqueous solutions by organic zeolites, II, Kinetics. Journal of the American Chemical Society, 69: 2836-2848.

Chang, C.Y., Sai, W.T.T., Ing, C.H., Chang, C.H. 2003. Adsorption of polyethylene glycol (PEG) from aqueous solution onto hydrophobic zeolite. Journal of Colloid and Interface Science, 260: 273-279.

Chang, S.H., Teng, T.T., Ismail, N. 2011. Screening of factors influencing $\mathrm{Cu}$ (II) extraction by soybean oil-based organic solvents using fractional factorial design. Journal of Environmental Management, 92: 2580-2585.

Crini, G. 2006. Non-conventional low-cost adsorbents for dye removal: A review. Bioresource Technology, 97: 1061-1085.

Freundlich, H.M.F. 1906. Over the adsorption in solution. Journal of Physical Chemistry A, 57: 385-470.

Gonçalves, J.O., Duarte, D.A., Dotto, G.L., Pinto, L.A.A. 2014. Use of Chitosan with different deacetylation degrees for the adsorption of food dyes in a binary system. CLEAN - Soil, Air, Water, DOI. 10. 1002/ clean.20120065.

Hameed, B.H., El-Khaiary, M.I. 2008. Sorption kinetics and isotherm studies of a cationic dye using agricultural waste: Broad bean peels. Journal of Hazardous Materials, 154: 639-648.

Han, R., Han, P., Cai, Z., Zhao, Z., Tang, M. 2008. Kinetics and isotherms of Neutral Red adsorption on peanut husk. Journal of Environmental Sciences, 20: 1035-1041.

Hanafiah, M.A.K.M., Ngah, W.S.W., Zolkafly, S.H., Teong, L.C., Majid, Z.A.A. 2012. Acid Blue 25 adsorption on base treated (Shorea dasyphylla) sawdust: Kinetic, isotherm, thermo dynamic and spectroscopic analysis. Journal of Environmental Sciences, 24: 261-268.

Lagergren, S. 1898. About the theory of so-called adsorption of soluble substances. Kungliga Svenska Vetenskapsa kademiens Handlingar, 24: 1-39.

Langmuir, I. 1916. The constitution and fundamental properties of solids and liquids. Part I. Solids. Journal of the American Chemical Society, 38: 2221-2295.

Low, L.W., Teng, T.T., Ahmad, A., Morad, N., Wong, Y.S. 2011. A novel pretreatment method of lignocellulosic material as adsorbent and kinetic study of dye waste adsorption. Water, Air, \& Soil Pollution, 218: 293-306.

Meng, F.W. 2005. Study on a Mathematical Model in Predicting Breakthrough Curves of Fixed-bed Adsorption onto Resin Adsorbent. MS Thesis, pp. 28-36, Nanjing University, China.

Mohan, S.V., Ramanaiah, S.V., Sarma, P.N. 2008. Biosorption of direct azo dye from aqueous phase onto Spirogyra sp. I02: Evaluation of kinetics and mechanistic aspects. Biochemical Engineering Journal, 38: 61-69.

Noroozi, B., Sorial, G.A. 2013. Applicable models for multi-component adsorption of dyes: A review. Journal of Environmental Sciences, 25: 419-429.

Palma, C., Contreras, E., Urra, J., Martinez, M.J. 2011. Ecofriendly technologies based on banana peel use for the decolourization of the dyeing process wastewater. Waste 
and Biomass Valorization, 2: 77-86.

Ponnusami, V., Krithika, V., Madhuram, R. Srivastava, S.N. 2007. Biosorption of reactive dye using acidtreated rice husk: Factorial design analysis. Journal of Hazardous Materials, 142: 397-403.

Prigione, V., Grosso, I., Tigini, V., Anastasi, A., Varese, G.C. 2012. Fungal waste-biomasses as potential low-cost biosorbents for decolorization of textile wastewaters. Water, 4: 770-784.

Punjongharn, P., Meevasana, K., Pavasant, P. 2008. Influence of particle size and salinity on adsorption of basic dyes by agricultural waste: dried Seagrape (Caulerpa lentillifera). Journal of Environmental Sciences, 20: 760-768.

Royer, B., Cardoso, N.F., Lima, E.C., Vaghetti, J.C., Simon, N.M., Calvete, T.,Veses, R.C. 2009. Applications of Brazilian-pine fruit shell in natural and carbonized forms as adsorbents to removal of methylene blue from aqueous solutions-kinetic and equilibrium study. Journal of Hazardous Materials, 164: 1213-1222.

Sivaraj, R., Namasivayam, C., Kadirvelu, K. 2001. Orange peel as an adsorbent in the removal of acid violet 17 (acid dye) from aqueous solutions. Waste Management, 21: 105-110.

Sun, Q., Yang, L. 2003. The adsorption of basic dyes from aqueous solution on modified peat-resin particle. Water Research, 37: 1535-1544.

Verma, A.K., Dash, R.R., Bhunia, P. 2012. A review on chemical coagulation/flocculation technologies for removal of colour from textile wastewaters. Journal of Environmental Management, 93: 154-168.

Wang, H.L., Chen, J.L., Zhai, Z.C. 2004. Study on thermodynamics and kinetics of adsorption of $p$ toluidine from aqueous solution by hyper-crosslinked polymeric adsorbents. Environmental Chemistry, 23: 188-192.

Wilczak, A., Keinath, T.M. 1993. Kinetics of sorption and desorption of copper(II) and lead(II) on activated carbon. Water Environment Research, 65: 238-244.

$\mathrm{Wu}, \mathrm{X}, \mathrm{Wu}, \mathrm{D} ., \mathrm{Fu}, \mathrm{R} .2007$. Studies on the adsorption of reactive brilliant red $\mathrm{X}-3 \mathrm{~B}$ dye on organic and carbon aerogels. Journal of Hazardous Materials, 147: $1028-1036$.

Xi, Z., Chen, B. 2014. Removal of polycyclic aromatic hydrocarbons from aqueous solution by raw and modified plant residue materials as biosorbents. Journal of Environmental Sciences, 26: 737-748.

Zhang, G., Yi, L., Deng, H., Sun, P. 2014. Dyes adsorption using a synthetic carboxymethyl cellulose-acrylic acid adsorbent. Journal of Environmental Sciences, 26: 1203-1211.

Zhang, W., Yan, H., Li, H., Jiang, Z., Dong, L., Kan, X., Yang, H., Li, A., Cheng, R. 2011. Removal of dyes from aqueous solutions by straw based adsorbents: Batch and column studies. Chemical Engineering Journal, 168: 1120-1127. 